Article

\title{
Crop Mapping Using PROBA-V Time Series Data at the Yucheng and Hongxing Farm in China
}

\author{
Xin Zhang, Miao Zhang, Yang Zheng and Bingfang Wu *
}

Key Laboratory of Digital Earth Science, Institute of Remote Sensing and Digital Earth, Chinese Academy of Sciences, Olympic Village Science Park, W. Beichen Road, Beijing 100101, China; zhangxin1010@radi.ac.cn (X.Z.); zhangmiao@radi.ac.cn (M.Z.); zhengyang@radi.ac.cn (Y.Z.)

* Correspondence: wubf@radi.ac.cn; Tel.: +86-10-6485-8721

Academic Editors: Clement Atzberger and Prasad S. Thenkabail

Received: 9 August 2016; Accepted: 26 October 2016; Published: 3 November 2016

\begin{abstract}
PROBA-V is a new global vegetation monitoring satellite launched in the second quarter of 2013 that provides data with a $100 \mathrm{~m}$ to $1 \mathrm{~km}$ spatial resolution and a daily to 10-day temporal resolution in the visible and near infrared (VNIR) bands. A major mission of the PROBA-V satellite is global agriculture monitoring, in which the accuracy of crop mapping plays a key role. In countries such as China, crop fields are typically small, in assorted shapes and with various management approaches, which deem traditional methods of crop identification ineffective, and accuracy is highly dependent on image resolution and acquisition time. The five-day temporal and $100 \mathrm{~m}$ spatial resolution PROBA-V data make it possible to automatically identify crops using time series phenological information. This paper takes advantage of the improved spatial and temporal resolution of the PROBA-V data, to map crops at the Yucheng site in Shandong Province and the Hongxing farm in Heilongjiang province of China. First, the Swets filter algorithm was employed to eliminate noisy pixels and fill in data gaps on time series data during the growing season. Then, the crops are classified based on the Iterative Self-Organizing Data Analysis Technique (ISODATA) clustering, the maximum likelihood method (MLC) and similarity analysis. The mapping results were validated using field-collected crop type polygons and high resolution crop maps based on GaoFen-1 satellite (GF-1) data in $16 \mathrm{~m}$ resolution. Our study showed that, for the Yucheng site, the cropping system is simple, mainly dominated by winter wheat-maize rotation. The overall accuracy of crop identification was $73.39 \%$ which was slightly better than the result derived from MODIS data. For the Hongxing farm, the cropping system is more complex (i.e., more than three types of crops were planted). The overall accuracy of the crop mapping by PROBA-V was $73.29 \%$ which was significantly higher than the MODIS product (46.81\%). This study demonstrates that time series PROBA-V data can serve as a useful source for reliable crop identification and area estimation. The high revisiting frequency and global coverage of the PROBA-V data show good potential for future global crop mapping and agricultural monitoring.
\end{abstract}

Keywords: PROBA-V; agriculture; crop mapping; time series analysis; cluster analysis

\section{Introduction}

The demand for accurate and reliable satellite-derived estimations and predictions of crop features and output keeps increasing [1-3]. During the last several decades, crop monitoring models and applications using satellite images have been developed [4,5] and improved in five main areas: biomass and yields estimation, vegetation and water stress monitoring, crop acreage estimation, crop type proportion mapping and crop phenological development [6,7]. The accurate cropland mapping and identification of crop types can provide basically essential information for all crop monitoring 
applications [8,9]. Crop phenology monitoring can provide the timing and duration of the cropping cycle, which is essential for yield and biomass estimation [10,11].

The normalized difference vegetation index (NDVI) has commonly been used to detect vegetation features [12] by taking advantage of the reflective and absorptive characteristics of vegetation in the red and near-infrared portions of the electromagnetic spectrum [13,14]. In general, NDVI with finer spatial resolution results in better vegetation classification [15-17]. However, due to the similarity in the spectra of different crops and the diversity in growing stages of one crop type, it is difficult to identify types by improving spatial resolution only. In addition, the existing crop classification methods based on high spatial resolution image often requires image acquisition from a certain stage during the growing season [18], which makes it difficult to automate crop identification in a complex cropping system.

To overcome the shortage of crop classification based on single/multiple high spatial resolution data, time series images have been introduced. Time series analysis of remote sensing data typically provides a feasible tool for detecting phenology on a per pixel basis $[19,20]$, and the phenological information can aid crop identification [21-23]. Using a crop's phenological information on a pixel scale, the crop type can be identified automatically by using time series data [24,25]. However, time series images with high temporal resolution are typically noisy, affected by cloud cover, atmospheric perturbations, variable illumination and sensor system error. Such effects are increased when the temporal resolution increases [26,27]. Previous studies have described the noise effect on time series data, and several smoothing methods have been presented [28-32].

The reliance of phenology-based methods on time serious images determines the selection of the medium spatial and high temporal resolution data [33]. Initially, NDVI time series data were obtained from the Advanced Very High-Resolution Radiometer (AVHRR) at $1.09 \mathrm{~km}$ resolution $[34,35]$. Then, the Moderate Resolution Imaging Spectro-radiometer (MODIS) sensors offer time series products with a higher spatial resolution of $250 \mathrm{~m}$ [36-38]. In Europe, the SPOT (Système Pour l'Observation de la Terre) VEGETATION products also provide data with a $1 \mathrm{~km}$ resolution $[39,40]$.

These data usually comes with coarse spatial resolution, which is less capable of identifying crops in small to medium fields [41-43] because the mixed-pixel effect may seriously affect the classification accuracy $[44,45]$. In China, this limitation is more problematic due to the complexity of small-scale farmlands [27]. Obtaining data with suitable spatial and temporal resolution is still limited by the current state of satellite sensor technology $[46,47]$. PROBA-V (Project for On-Board Autonomy-Vegetation) is a "gap-filler mission" between SPOT-VGT and Sentinel-3 in the European COPERNICUS program, which was launched in the second quarter of $2013[48,49]$. PROBA-V provides $100 \mathrm{~m}$ resolution with global observation capability with a 2-3 days' repetition cycle and a daily global data at resolution of $300 \mathrm{~m}$, in the Visible and Near-infrared (VNIR) bands [50]. A spatial resolution of $100 \mathrm{~m}$ with high temporal resolution may enhance crop monitoring programs with respect to the previously available time series data [51].

In this study, we tested the hypothesis that with higher spatial and temporal resolution time series NDVI [52], PROBA-V can be used to improve crop mapping accuracy, especially for complex and small scale farmlands. The Yucheng site with very small scale farmlands and the Hongxing farm with a complex cropping system were chosen as study areas which represent two typical crop areas in China. The study design included data pre-processing, classification and extraction of the phenological parameters [53-55]. Field data and $16 \mathrm{~m}$ high resolution images from GaoFen-1 (GF-1) satellite were used to validate the mapping accuracy. In addition, we also derive crop phenology from the daily PROBA-V data with $300 \mathrm{~m}$ resolution and crop mapping, using TIMESAT software. (Lund University, Lund, Sweden, 22 April 2015, v3.2) [56]. 


\section{Materials}

\subsection{Study Area}

Two typical study areas in China belonging to the Joint Experiment of Crop Assessment and Monitoring (JECAM) were selected [57] (Figure 1). The Yucheng site in northwestern Shandong in eastern China extends from $36.69^{\circ} \mathrm{N}$ to $37.20^{\circ} \mathrm{N}$ and from $116.37^{\circ} \mathrm{E}$ to $116.75^{\circ} \mathrm{E}$. Yucheng is a predominantly agricultural area that is representative of farming practices in the North China Plain. According to the meteorological station data provided by the Climate Database of China Meteorological Administration (CMA), Yucheng has a temperate, semi-arid monsoon climate, with a mean annual temperature of $13.1^{\circ} \mathrm{C}$ and a precipitation of $582 \mathrm{~mm}$, concentrated from late June to September. Crops are typically winter wheat followed by summer maize. The crop calendar for winter wheat is from mid-October to early June of the next year, and for maize it is from mid-June to end of September [58].

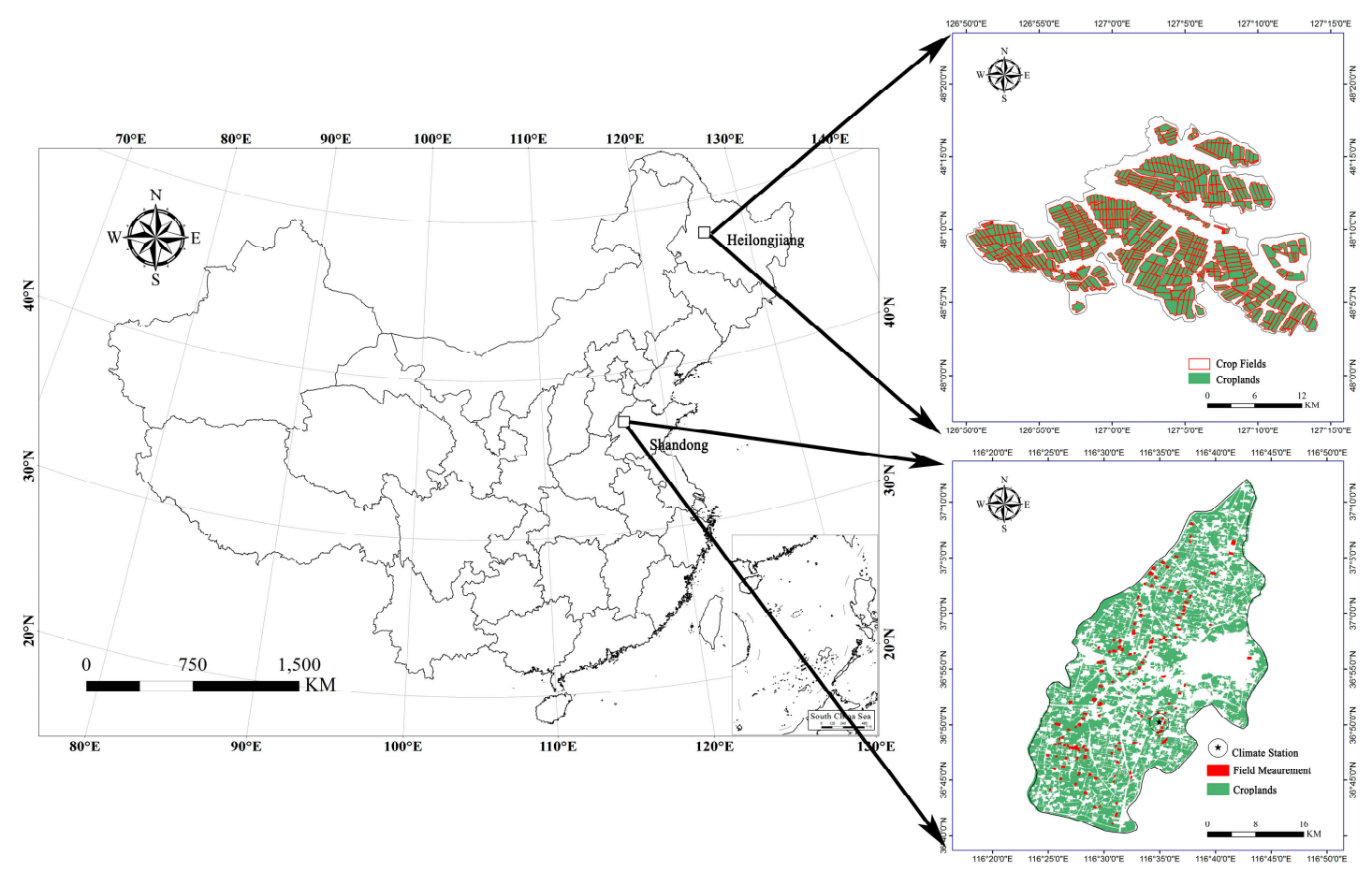

Figure 1. The Yucheng site in Shandong province and the Hongxing farm in Heilongjiang Province were selected as study areas. Green shading indicates croplands. The red boxes and solid squares indicate the places where ground measurement was carried out.

The other study area is the Hongxing farm, which is located in the north of Heilongjiang province in the northeast of China $\left(48.15^{\circ} \mathrm{N}, 127.01^{\circ} \mathrm{E}\right)$. CMA data indicates an average temperature of $22.5^{\circ} \mathrm{C}$ and a mean annual precipitation of $555 \mathrm{~mm}$, concentrated from July to September. The dominant land uses are cropping, forests and residential areas, with few roads, and little water or grasslands. Th major crops are soybean, maize and spring wheat. The crop calendar for major crops spans from May to November [59].

\subsection{Satellite Data}

PROBA-V provides global coverage with spatial resolutions from $100 \mathrm{~m}$ to $1 \mathrm{~km}$. The sensor has three cameras that provide a $2250 \mathrm{~km}$ swath image. The S1TOC (Top of Canopy) products provide daily surface reflectance and NDVI corrected for atmospheric effects at $300 \mathrm{~m}$ resolution by combining the strips from the three cameras. The central camera covers a swath of approximately $517 \mathrm{~km}$ at $100 \mathrm{~m}$ resolution, which ensures global land coverage every 5 days (Figure 2). Synthetic 5 day $100 \mathrm{~m}$ 
resolution data (S5TOC) are derived from best-quality daily synthesis surface reflectance and NDVI after atmosphere correction $[49,60]$. To cover the whole study area, both S1TOC and S5TOC products were selected for this study.

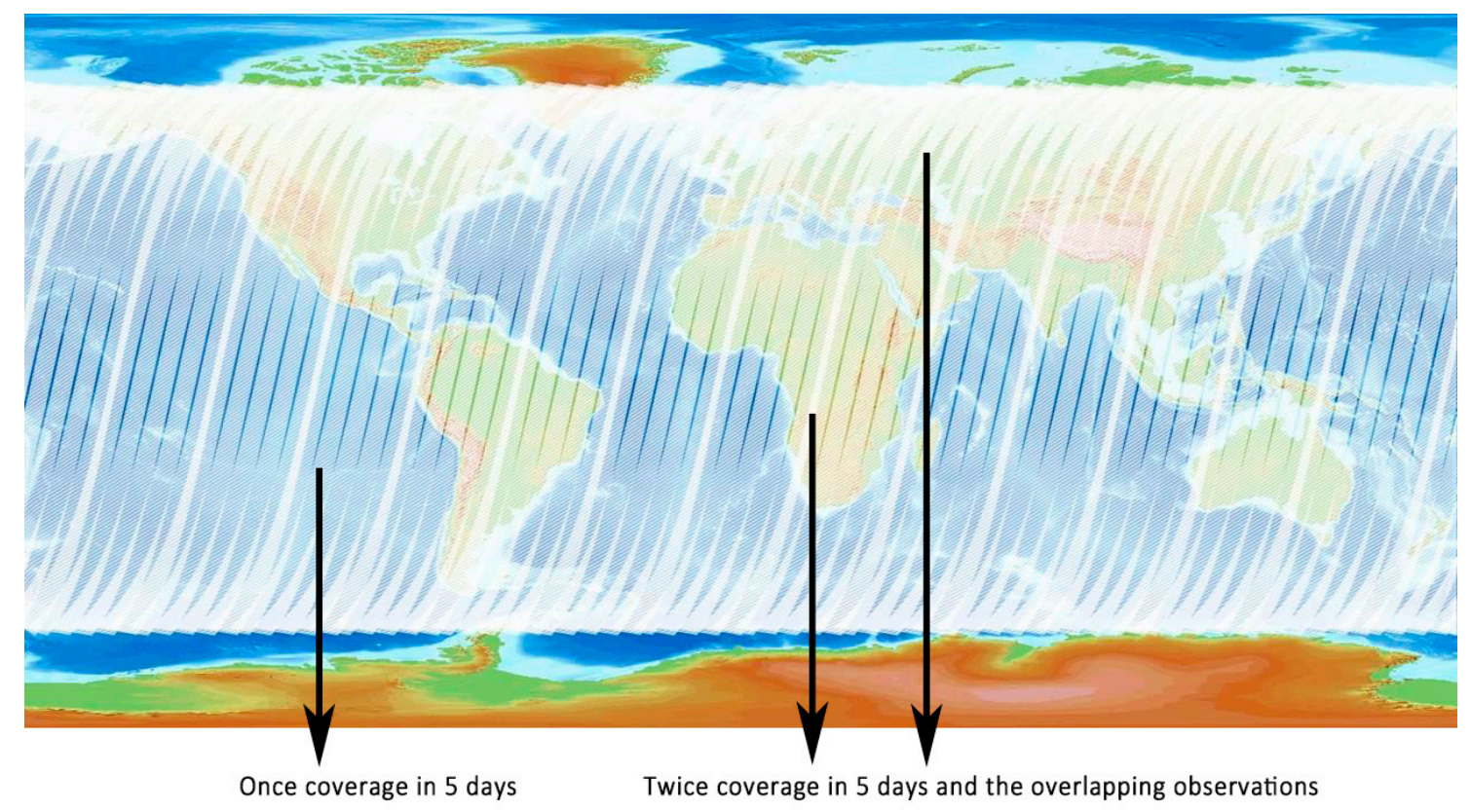

Figure 2. Overview of the $100 \mathrm{~m}$ coverage after 5 days. The brighter white areas indicate overlapping observations [60].

To cover all crop growing stages in both areas, we collected images at the times shown in Table 1. Additionally, the MODIS 16-day NDVI products (MOD13Q1) at $250 \mathrm{~m}$ resolution were downloaded for comparison.

\subsection{Validation Data}

Field crop type data were used to validate the classification. At the Yucheng site, field data were acquired in 2015 from April 10 to 2 for wheat and from August 10 to 20 for maize. A handheld global positioning system (GPS) with a positional accuracy of $<5 \mathrm{~m}$ was used to record the location $[61,62]$. We collected 146 points including 37 for wheat and 109 for maize. Comprehensive crop mapping at a high resolution $(16 \mathrm{~m})$ by visual interpretation and supervised classification based on GF-1 images was also used to validate the classification. At the Hongxing farm, the detailed crop type proportion in 571 fields in 2014 was retrieved from the local planting scheme.

We also collected the phenology information of wheat, maize and soybean in both study areas. The observed phenological times for each crop are shown in Table 4.

\section{Methods}

Three main steps were performed with MODIS and PROBA-V images at the Yucheng site and Hongxing farm: Data pre-processing; Classification and Extraction of the phenological parameters (Figure 3). In this study, the PROBA-V S5TOC $100 \mathrm{~m}$ NDVI and MOD13Q1 $250 \mathrm{~m}$ NDVI data are used for crop mapping. The crop mapping result and PROBA-V S1TOC $300 \mathrm{~m}$ NDVI data are used to monitor crop phenology. 


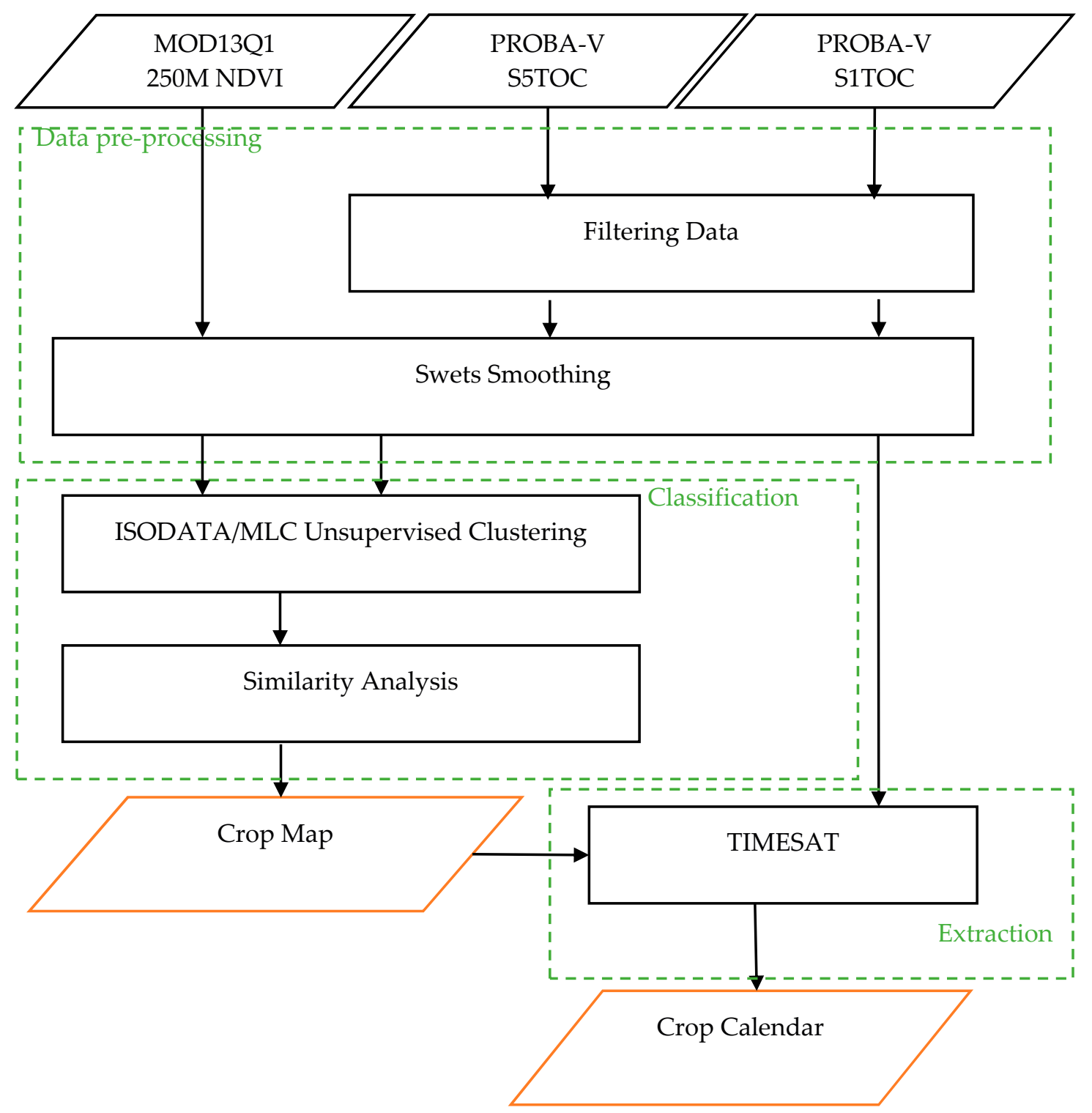

Figure 3. Flowchart of the crop map and crop calendar processing.

\subsection{Data Pre-Processing}

\subsubsection{Filtering Data}

Due to the cloud and snow or other weather conditions and the physical limitations of the sensor, high temporal time series images often appear as invalid pixels, which affects the smoothing results (Figure 4). The pixels where the quality flag indicated missing, cloud, snow, sea and background were designated as invalid pixels. A simple filter was used to reduce data deficiencies prior to smoothing. The images for which the invalid pixel percentage is greater than $60 \%$ were designated as invalid. During the whole growing season, the S5TOC $100 \mathrm{~m}$ data availability percentages are $72 \%$ and $95 \%$, and the S1TOC $300 \mathrm{~m}$ data availability percentages are $67 \%$ and $87 \%$, in Yucheng and Hongxing, respectively. Results are shown in Table 1. The availability percentage in Hongxing is significantly higher than that in Yucheng due to the better coverage of polar-orbiting satellite in high latitudes: twice coverage in Hongxing and once in most of Yucheng (Figure 2). 


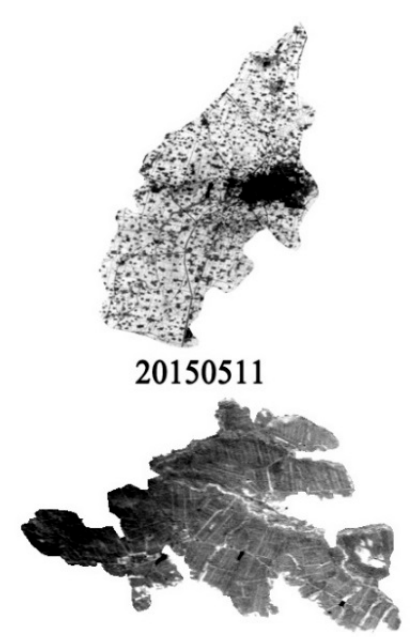

20140501

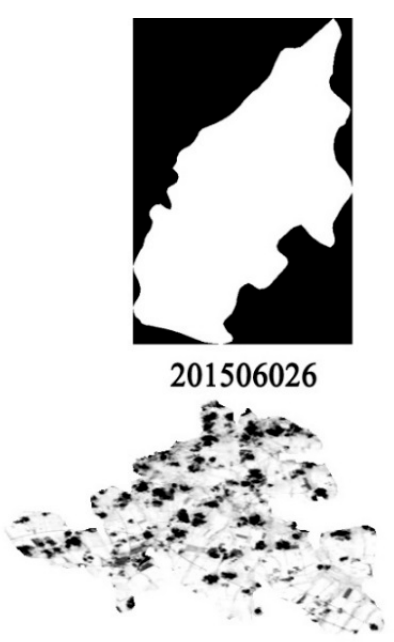

20140801

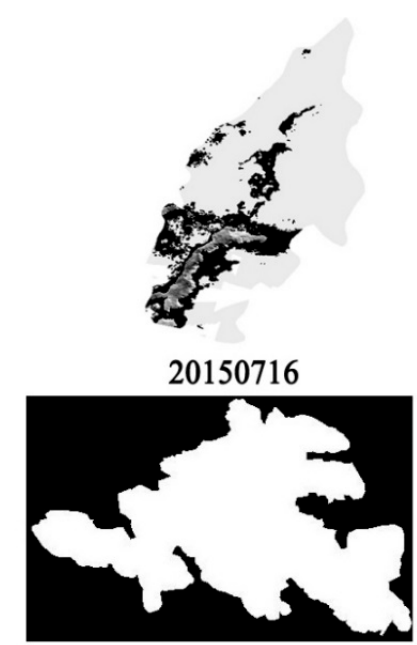

20140921

Figure 4. The PROVBA-V data at the Yucheng site and Hongxing farm. The images with more than 60\% invalid pixels are designated as invalid data (26 June 2015-16 July 2015 at the Yucheng site and 1 August 2014-21 September 2014 at the Hongxing farm).

Table 1. The percentage of the images with less than $60 \%$ invalid pixels from PROBA-V in Yucheng and Hongxing during growing season. Invalid pixels indicate that values are missing, cloud, snow, sea and background. Images in which invalid pixels account for more than $60 \%$ are not used because it would adversely affect the smoothing result.

\begin{tabular}{lccccc}
\hline Location & Data & Time & $\begin{array}{c}\text { Number of } \\
\text { Images }\end{array}$ & $\begin{array}{c}\text { Invalid } \\
\text { Images }\end{array}$ & $\begin{array}{c}\text { Percentage of Images } \\
\text { Used for Smoothing }\end{array}$ \\
\hline \multirow{2}{*}{ Yucheng } & S5 $100 \mathrm{~m}$ & 1 October 2014-26 September 2015 & 72 & 20 & $72 \%$ \\
& S1 300 m & 1 October 2014-30 September 2015 & 365 & 120 & $67 \%$ \\
\hline \multirow{2}{*}{ Hongxing } & S5 $100 \mathrm{~m}$ & 1 May 2014-26 November 2014 & 42 & 2 & $95 \%$ \\
& S1 300 m & 1 May 2014-30 November 2014 & 213 & 28 & $87 \%$ \\
\hline
\end{tabular}

\subsubsection{Smoothing}

An efficient smoothing method can remove noise in NDVI time series. SPIRITS (Software for the Processing and Interpretation of Remotely Sensed Image Time Series [55]) which was developed by PROBA-V data provider gives four smoothing options, including MEAN (Interpolate missing values \& apply Running Mean Filter RMF), BISE (Best Index Slope Extraction), Swets and Whittaker [63]. We chose the Swets method [64] which uses a weighted least-squares linear regression and moving window to reduce contamination and provide a continuous temporal NDVI signal. This approach generates a smoothed NDVI profile by filling missing data. The resulting relationship between the smoothed curve and the original data is statistically based.

\subsection{Classification}

We applied an unsupervised classification based on the Iterative Self-Organizing Data Analysis Technique (ISODATA) clustering and maximum likelihood method (MLC) analysis implemented by SPIRITS, to S5TOC $100 \mathrm{~m}$ PROBA-V NDVI images during the growing season after filtering and smoothing. We tried from five to 10 categories for classification to ensure the best results, and found five and six categories to be the best choices for the Yucheng site and the Hongxing farm, respectively, because adding more categories to the classification did not significantly change the results. Then, using the spectral-temporal information of each crop collected in the field, we used a similarity analysis to ensure the crop type of the ISODATA clustering results. Procedures were repeated for the MODIS 16-day NDVI $250 \mathrm{~m}$ resolution images for comparison. 


\subsection{Extraction of Phenological Parameters}

Crop maps were derived and validated in the last working step based on the PROBA-V S5 $100 \mathrm{~m}$ NDVI data. Using the crop map, the NDVI profile for each crop during the growing season was generated by averaging PROBA-V S1 $300 \mathrm{~m}$ NDVI daily data for each crop type mask. TIMESAT is the most commonly used software for extracting phenological variables based on thresholds, assuming that a specific phenology is present when the NDVI exceeds a set threshold $[65,66]$. In this study, we used the amplitude method in TIMESAT to delineate the beginning and end of the season by setting the proportion of the seasonal amplitude measured from the left and right minimum values, respectively.

To obtain the seasonal parameters with TIMESAT from only one year of data (At least 3-year data is required in TIMESAT), we constructed an artificial time-series spanning three years by duplicating the one-year time-series data. Then, the phenology for each crop was extracted including the beginning of the season, the end of the season and the time of seasonal peak. In this study, we assumed that the start of the season, the peak time and the end of the season were the same as the emergence, flowering and harvest stages in the crop calendar [21,45].

\section{Results}

\subsection{Crop Mapping}

The crops are typically winter wheat followed by summer maize at the Yucheng site. To obtain the best classification result, five cluster types were selected by the ISODATA/MLC clustering of the NDVI time series data. Based on the crop type proportion in the study area, only one type of crop can be identified. We combined the clusters identified as having similar time series profiles, and designated two types by similarity analysis: Wheat-maize double cropping and other. A high resolution crop map retrieved through visual interpretation and supervised classification with the field measurement points based on a GF-1 $16 \mathrm{~m}$ resolution image was used as the field survey for validation. Figure 5 displays the classification results which are, in order, the PROBA-V result, the MODIS result and the field survey, with the measured points attached. As shown in Figure 5a,b, the wheat-maize in the PROBA-V result and the MODIS result were divided into two areas on the map (Blue and Red color). Yucheng is in a scan-to-scan overlapping observation area of PROBA-V and MODIS satellites. The bowtie effect between two strips on the overlap led to an apparent stripping effect on the classification results [67].

The confusion matrix method was used to verify the classification accuracy, the overall accuracies, and kappa for the classification results from PROBA-V images and MODIS images are $73.39 \%$, $70.62 \%$ and $0.44,0.38$, respectively (Table 2). For the result based on PROBA-V images, $84.38 \%$ of all of wheat-maize pixels in Yucheng were identified correctly, and $73.69 \%$ of the pixels classified as wheat-maize were indeed crops. Likewise, $83.36 \%$ of all wheat-maize pixels were identified, and $70.98 \%$ of the pixels classified as wheat-maize were indeed crops, as per the MODIS images. A validation using 146 ground measured points indicated that the PROBA-V results succeeded in assigning 143 out of 146 points correctly, compared with 132 points recognized from the MODIS results.

The Hongxing farm employs a much more complex cropping system. Soybean (281), wheat (26), maize (256), vegetables (3) and potatoes (5) are growing in 571 fields, and the growing seasons of different crops are all concentrated in the second half of the year, which makes crop classification difficult. To identify more crops, we tried out 5-10 clusters in the unsupervised cluster analysis, and 6 clusters were selected as the parameter for this process (Having more than 6 clusters did not yield more crop types). Due to the limitation of current image quality and technology, 8 vegetables and potato fields were still not identifiable. The crop map produced using the PROBA-V images and MODIS images are shown in Figure 6. Figure 6c shows the planting schedule in 2014. The PROBA-V results clearly indicated three crops, including soybean, wheat and maize. Due to the closed growing seasons and NDVI values for soybean and maize (Figure 7), we could not identify these two crops from the MODIS images, no matter how the parameters of the ISODATA/MLC clustering analysis were adjusted. The classification accuracies of the images from the two sensors are shown in Table 3. 


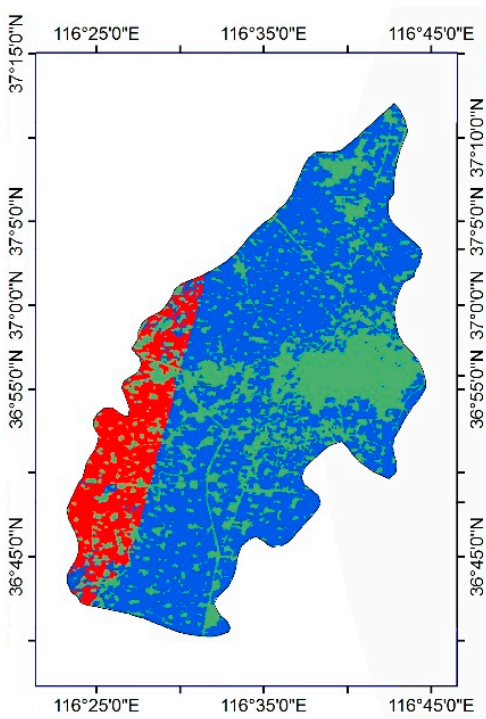

Wheat-maize double cropping

(a)

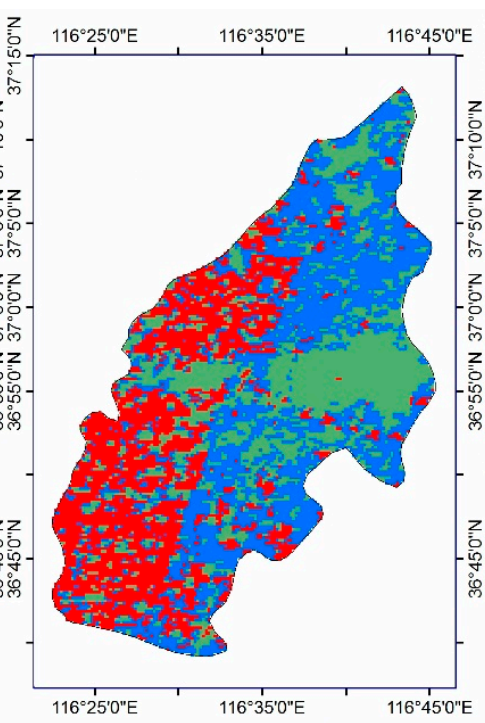

Other

(b)

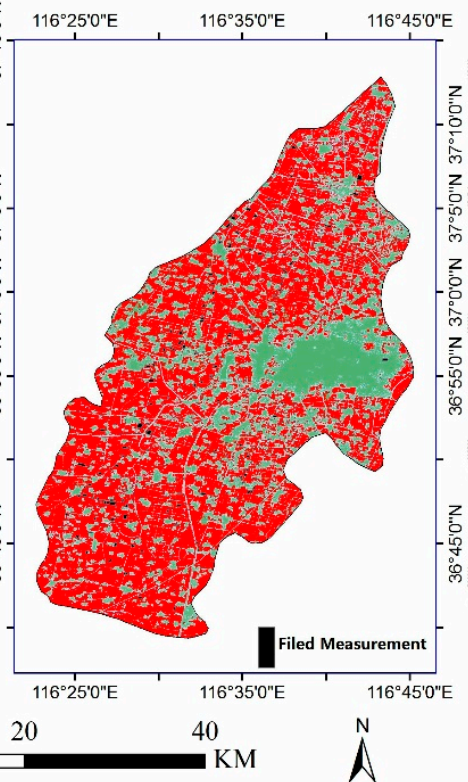

(c)

Figure 5. (a,b) Classification results based on PROBA-V and MODIS data in Yucheng. (c) Validation data is generated from $16 \mathrm{~m}$ high resolution data and field measurements. In $(\mathbf{a}, \mathbf{b})$, the crop (wheat followed maize) are classified into two parts (red and blue) due to the sensor overlapping characteristic.

Table 2. The classification accuracies of the images from PROBA-V and MODIS at Yucheng site.

\begin{tabular}{|c|c|c|c|c|c|}
\hline \multicolumn{6}{|c|}{ Proba-V Classification } \\
\hline \multicolumn{6}{|c|}{ Reference Data } \\
\hline & Wheat-Maize & Other & Total & User Acc. & Commission \\
\hline Wheat-Maize & 48,592 & 17,351 & 65,943 & $73.69 \%$ & $26.31 \%$ \\
\hline Other & 9052 & 24,245 & 33,297 & $72.81 \%$ & $27.19 \%$ \\
\hline Total & 57,644 & 41,596 & 99,240 & & \\
\hline Prod. Acc. & $84.30 \%$ & $58.29 \%$ & & & \\
\hline Omission & $15.70 \%$ & $41.71 \%$ & & & \\
\hline \multicolumn{6}{|c|}{$\begin{array}{c}\text { Overall Accuracy }=\mathbf{7 3 . 3 9 \%} \text {, Kappa Coefficient }=\mathbf{0 . 4 4} \\
\text { Field Accuracy }=143 / 146(97.85 \%)\end{array}$} \\
\hline \multicolumn{6}{|c|}{ MODIS Classification } \\
\hline \multicolumn{6}{|c|}{ Reference Data } \\
\hline & Wheat-Maize & Other & Total & User Acc. & Commission \\
\hline Wheat-Maize & 7270 & 2973 & 10,243 & $70.98 \%$ & $29.02 \%$ \\
\hline Other & 1451 & 3366 & 4817 & $69.88 \%$ & $30.12 \%$ \\
\hline Total & 8721 & 6339 & 15,060 & & \\
\hline Prod. Acc. & $83.36 \%$ & $53.10 \%$ & & & \\
\hline Omission & $16.64 \%$ & $46.90 \%$ & & & \\
\hline \multicolumn{6}{|c|}{$\begin{array}{c}\text { Overall Accuracy }=\mathbf{7 0 . 6 2} \% \text {, Kappa Coefficient }=\mathbf{0 . 3 8} \\
\text { Field Accuracy }=132 / 146(90.41 \%)\end{array}$} \\
\hline
\end{tabular}



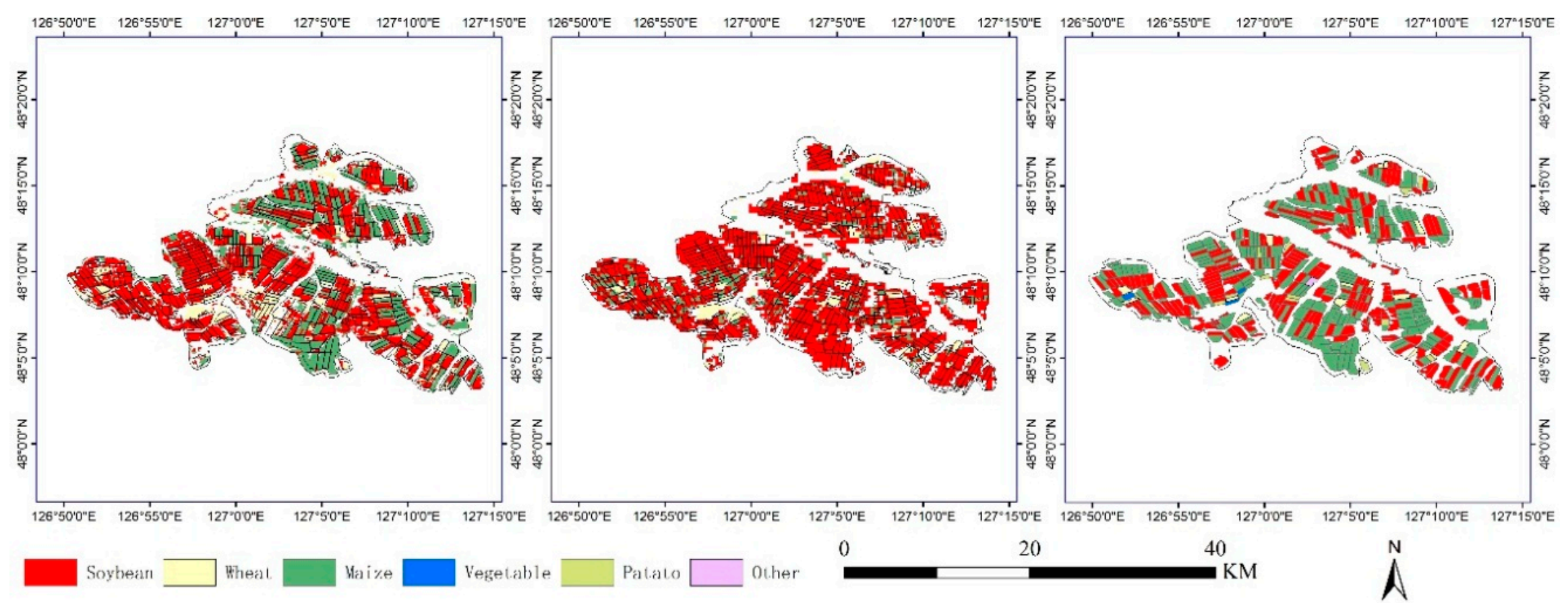

(a)

(b)

(c)

Figure 6. (a,b) Classification results based on PROBA-V and MODIS data; (c) Field crop type proportion at the Hongxing farm 


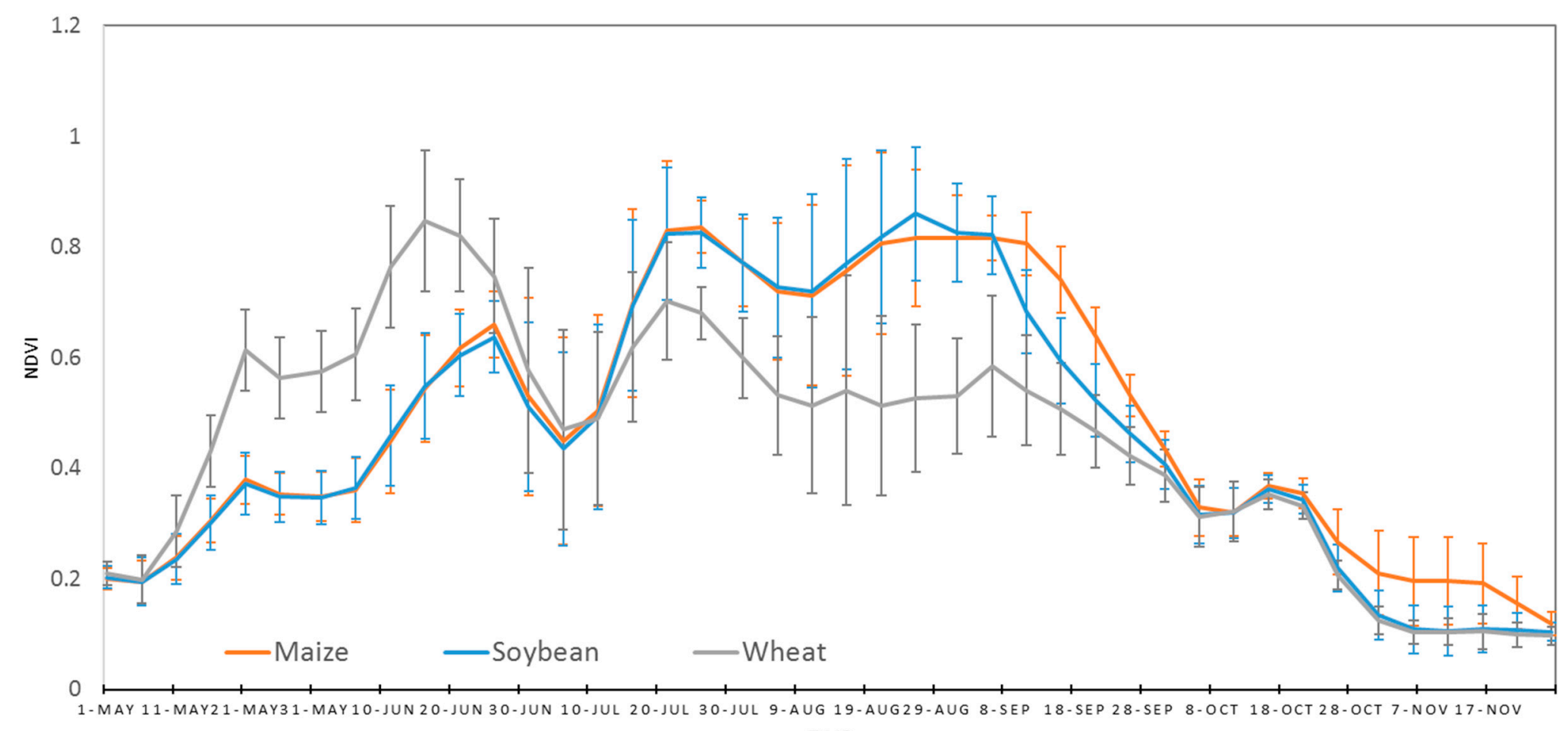

$100 \mathrm{~m}$ data. 
Table 3. Classification accuracies of the images from PROBA-V and MODIS at the Hongxing farm.

\begin{tabular}{|c|c|c|c|c|c|c|}
\hline \multicolumn{7}{|c|}{ Proba-V Classification } \\
\hline \multicolumn{7}{|c|}{ Reference Data } \\
\hline & Maize & Soybean & Wheat & Total & User Acc. & Commission \\
\hline Maize & 6581 & 1322 & 33 & 7936 & $82.93 \%$ & $17.07 \%$ \\
\hline Soybean & 4104 & 8862 & 82 & 13,048 & $67.92 \%$ & $32.08 \%$ \\
\hline Wheat & 225 & 362 & 1372 & 1959 & $70.04 \%$ & $29.96 \%$ \\
\hline Total & 10,910 & 10,546 & 1487 & 22,943 & & \\
\hline Prod. Acc. & $60.32 \%$ & $84.03 \%$ & $92.27 \%$ & & & \\
\hline Omission & $39.68 \%$ & $15.97 \%$ & $7.73 \%$ & & & \\
\hline \multicolumn{7}{|c|}{ Overall Accuracy $=\mathbf{7 3 . 2 9} \%$, Kappa Coefficient $=\mathbf{0 . 5 3}$} \\
\hline \multicolumn{7}{|c|}{ MODIS Classification } \\
\hline \multicolumn{7}{|c|}{ Reference Data } \\
\hline & Maize & Soybean & Wheat & Total & User Acc. & Commission \\
\hline Maize & 142 & 214 & 5 & 361 & $39.34 \%$ & $60.66 \%$ \\
\hline Soybean & 1164 & 1036 & 7 & 2207 & $46.94 \%$ & $53.06 \%$ \\
\hline Wheat & 10 & 9 & 62 & 81 & $76.54 \%$ & $23.46 \%$ \\
\hline Total & 1316 & 1259 & 74 & 2649 & & \\
\hline Prod. Acc. & $10.84 \%$ & $82.42 \%$ & $83.78 \%$ & & & \\
\hline Omission & $89.16 \%$ & $17.58 \%$ & $16.22 \%$ & & & \\
\hline \multicolumn{7}{|c|}{ Overall Accuracy $=\mathbf{4 6 . 8 1} \%$, Kappa Coefficient $=0.01$} \\
\hline
\end{tabular}

The overall accuracies and kappa for the classification results based on PROBA-V images and MODIS images were $73.29 \%, 46.81 \%$ and $0.53,0.01$, respectively. For the PROBA-V-based result, $60.32 \%$ of maize, $84.03 \%$ of soybean and $92.27 \%$ of Wheat at Hongxing farm were identified correctly. Only $10.84 \%$ of maize, $82.42 \%$ of soybean and $83.78 \%$ of wheat were correctly classified from the MODIS-based result. For wheat, due to the significantly different NDVI growth curve, the accuracy was close for PROBA-V and MODIS based results. However, the MODIS images at $250 \mathrm{~m}$ resolution could not differentiate soybean from maize correctly. Out of the 256 maize fields at the Hongxing farm, only 18 fields were successfully recognized by MODIS, and the product accuracy and user accuracy for maize were only $10.84 \%$ and $39.34 \%$.

\subsection{Crop Phenology}

At the Yucheng site, according to the local crop characteristics (typically winter wheat followed by summer maize.), we set the number of seasons to 2 and the amplitude threshold for the beginning and end of the season as 0.1 in the TIMESAT software. The TIMESAT results and observed crop seasonal parameters are shown in Figure 8. The gaps between TIMESAT results and observed results for winter wheat and summer maize at the Yucheng site are less than 10 days (Table 4).

The Hongxing farm has a complex cropping system, with more than 5 crop types planted at one time. The PROBA-V and MODIS images identified only three types: soybean, maize and wheat. At the Hongxing farm, the crops are harvested soon after maturation for achieving the best economic value. Therefore, we assigned one growing season and the amplitude threshold was set differently for each crop in the TIMESAT software [59]. In this work, the amplitude thresholds for the beginning and the end of the season were set to 0.2 and 0.4 for maize, 0.2 and 0.8 for soybean and 0.1 and 0.5 for wheat, respectively.

Maize and soybean have similar phenological characteristics in that the emergency and flowering date are closed, however, the major difference is that maize has a longer growing season and is harvested later. The phenology monitoring result between observed and TIMESAT are shown in Figure 9. With the precise amplitude thresholds, the gaps between the observed phenology and the TIMESAT result for the three phenology stage were less than 10 days. 


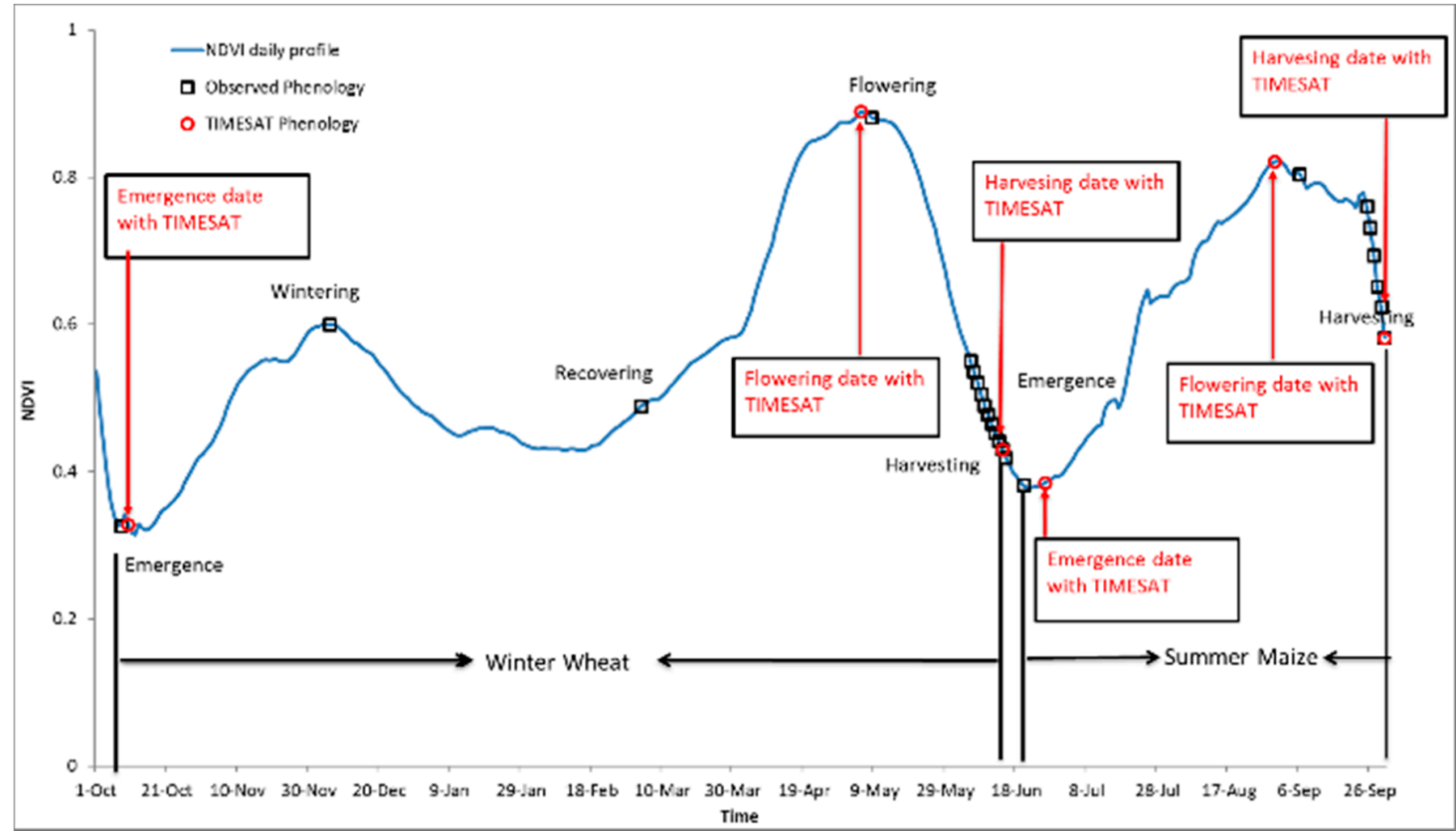

Figure 8. The crop NDVI curve in Yucheng during the growing season. The black squares and red circles are the phenology date obtained by ground measurement and TIMESAT, respectively.

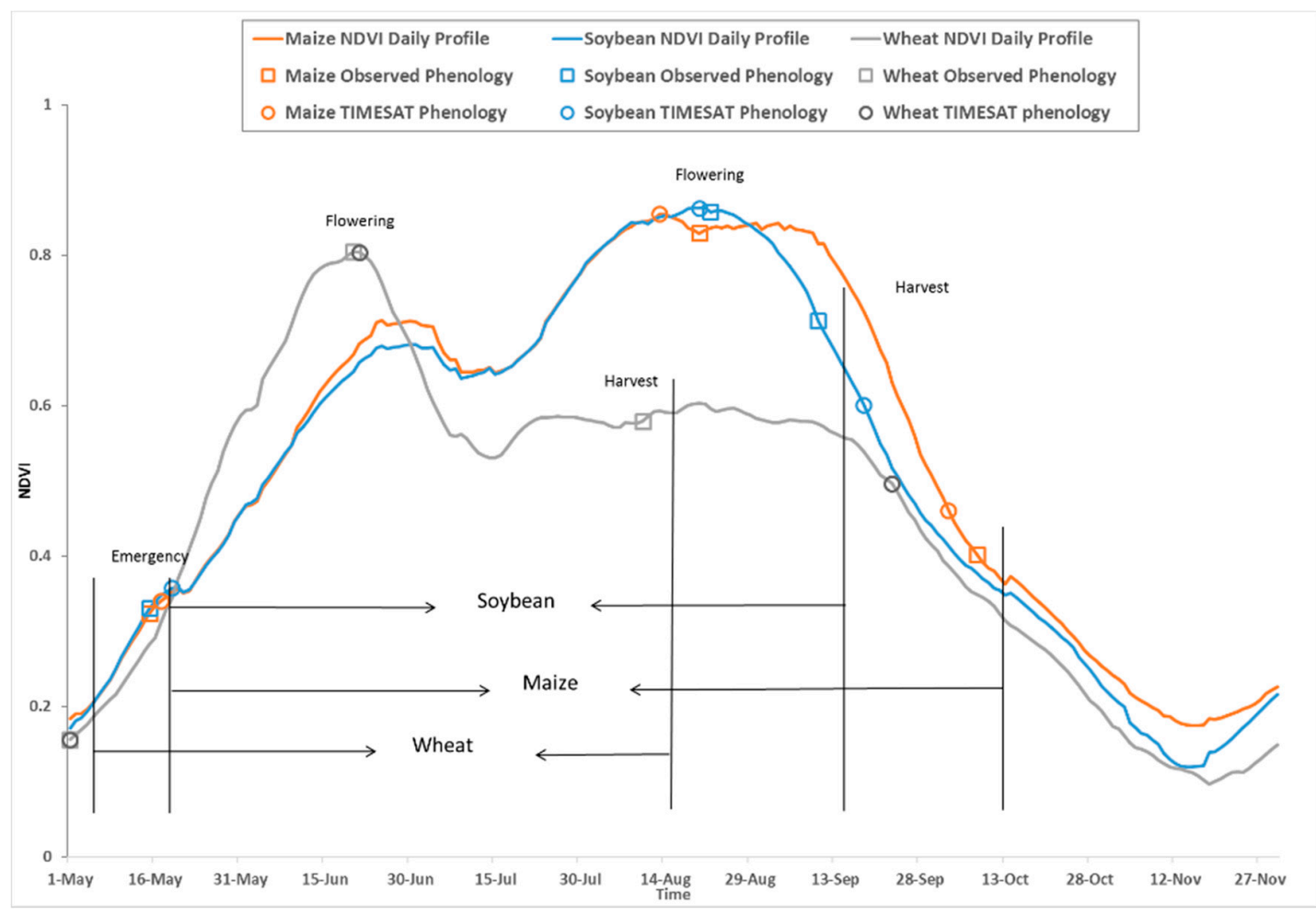

Figure 9. Maize, soybean and wheat NDVI curves at the Hongxing farm during the growing season. The colored squares and circles are the phenology date obtained by ground measurements and TIMESAT, respectively.

For wheat, the gaps between the observed phenology and the TIMESAT result for the emergence and flowering stages were less than 1 day. After harvest, the wheat straw was always left on the farm as fertilizer and was shown on the NDVI time series curve as a flat line after the maturity stage, which 
made it difficult to identify the actual harvest time. The gap between observed and TIMESAT results for harvest of wheat at the Hongxing farm is 44 days.

Table 4. The phenology date obtained from ground data and TIMESAT. The red number means the gap between our results and observed date exceeded 10 days.

\begin{tabular}{|c|c|c|c|c|c|}
\hline Location & Crop & Phenology/Farm Operation & Observed & TIMSAT Result & Gap \\
\hline \multirow{8}{*}{ Yu Cheng } & \multirow{5}{*}{ Winter wheat } & Emergence & 8 October & 10 October & 2 \\
\hline & & Wintering & 6 December & & \\
\hline & & Tillering & $4 \mathrm{March}$ & & \\
\hline & & Flowering & 8 May & 5 May & 3 \\
\hline & & Harvest & 5-15 June & 14 June & 0 \\
\hline & \multirow{3}{*}{ Summer maize } & Emergence & 20 June & 26 June & 6 \\
\hline & & Flowering & 6 September & 30 August & 7 \\
\hline & & Harvest & 20-30 September & 30 September & 0 \\
\hline \multirow{9}{*}{ Hongxing } & \multirow{3}{*}{ Maize } & Emergence & 15 May & 17 May & 2 \\
\hline & & Flowering & 20 August & 13 August & 7 \\
\hline & & Harvest & 8 October & 3 October & 5 \\
\hline & \multirow{3}{*}{ Soybean } & Emergence & 15 May & 19 May & 4 \\
\hline & & Flowering & 22 August & 20 August & 2 \\
\hline & & Harvesting & 10 September & 18 September & 8 \\
\hline & \multirow{3}{*}{ Wheat } & Emergence & 1 May & 1 May & 0 \\
\hline & & Flowering & 21 June & 20 June & 1 \\
\hline & & Harvest & 10 August & 23 September & 44 \\
\hline
\end{tabular}

\section{Discussion}

The PROBA-V NDVI time series images provide an effective and accurate crop mapping in comparison with existing crop identification studies. As a continuation of the SPOT-5 program, PROBA-V was designed to offer a global coverage at spatial resolutions of $100 \mathrm{~m}, 300 \mathrm{~m}$ and $1 \mathrm{~km}$ [49]. It was used as the medium resolution remote sensing resource instead of SPOT-VEGETATION in the European MARS crop yield forecasting system [68].

The overall accuracy of crop identification at a location with only one type of crop was $73.39 \%$, which was slightly better than the MODIS results. When the plant mix became complex (i.e., more than three crop types within a study area, a very common situation in China), the overall accuracy of crop mapping using PROBA-V was $73.29 \%$, which was much better than the MODIS result of $46.81 \%$. Roumenina studied crop identification by PROBA-V $100 \mathrm{~m}$ and $300 \mathrm{~m}$ data at the Zlatia Test Site in Bulgaria using the single and multiple time data [51]. The overall accuracy using single $100 \mathrm{~m}$ PROBA-V data reached $72.4 \%-86.2 \%$, and the multi time series data yielded an accuracy of $88.9 \%$, which was significantly better than the results using the MODIS $250 \mathrm{~m}$ data. Our results support this conclusion.

A large proportion of China's cropland is managed through complex cropping and the crop field is usually small, which makes crop mapping difficult. Pittman generated a cropland map based on MODIS $250 \mathrm{~m}$ resolution for global country crop analysis. Their accuracy of cropland identification is $43 \%$ on a global scale and only $41 \%$ in China [69]. Fritz also validated the global cropland map developed from MODIS by crowdsourced data points from Geo-Wiki, and the accuracy was only 65\% for China [70]. The cropland map by the International for Applied Systems Analysis-The International Food Policy Research Institute (IIASA-IFPRI), which integrates several individual cropland maps at a global, regional or national scale, produced an overall accuracy of $82.4 \%$, according to the validation with very high resolution data by Fritz [71]. It is even more challenging to identify different crop types than cropland mapping. Our results for China show higher accuracy for crop mapping than the above analysis did. Because our results were based on two diverse regions in China, we believe that the PROBA-V data has the capacity to provide an alternative resource for global crop mapping. 
In fact, the crop field at Yucheng site is fragmented. The field size ranges from very small to small [71], which makes it more difficult to map the crop. Usually, in areas with large field sizes, medium resolution data can be used to monitor agriculture while small and very small field sizes would require very high resolution imagery in order to achieve higher accuracy [72]. However, most of the cultivated land in Yucheng is winter wheat followed by summer maize, which produces a unique NDVI time serious profile during growing season and makes it more obvious when using the time series data. In this study, $84.3 \%$ and $83.36 \%$ of crops were identified in Yucheng based on PROBA-V and MODIS due to the unique growing curve. The PROBA-V result yielded better accuracy than the MODIS result did, which confirms that the improved spatial resolution increased the quality of classification in very small to small field cropping systems.

At the Yucheng site, we identified two crop classes using both PROBA-V or MODIS time series data (Figure 5a,b). Figure 2 shows the PROBA-V $100 \mathrm{~m}$ data coverage over 5 days. The brighter, white areas are an overlap location where a bowtie effect appears due to the different scanning strips at different times in the PROBA-V synthesis products [73]. This bowtie effect also appeared for MODIS products and almost all of the cross-track-scanning imaging radiometers [74-76]. Many quick and efficient algorithms have been developed to remove these effects on single data $[67,77,78]$, but the impact of the bowtie effect on the time series classification still exists. Although the error can be easily removed by combining the two classes through visual interpretation, it still causes difficulty for automatic batch processing. The issue will be reduced by a satellite with a global coverage capacity at higher spatial and temporal resolution.

At the Hongxing farm, the field size ranges from small to medium. The difficulty of cropland detection at the Hongxing farm is lower than in Yucheng. However, the Hongxing farm has a more complex cropping system. Five crops' growing seasons occur in the second half of the year, which creates difficulties for crop mapping. The identification of maize and soybean is especially difficult as the crop growing curves of these two crops are very similar (Figure 9). Two NDVI curves peak only seven days apart (Table 4). In this study, the differentiation of maize and soybean with 16-day, $250 \mathrm{~m}$ MODIS NDVI failed at the Hongxing farm. Only $10.84 \%$ of maize was classified correctly. With most of the maize pixels identified as soybean, the commission error of soybean was $53.06 \%$. The overall accuracy based on MODIS data was only $46.81 \%$ and the classification agreement was poor $($ Kappa $=0.01)$. Due to the increased temporal resolution, 5-day PROBA-V NDVI product had better accuracy. Overall, $60.32 \%$ of maize and $84.03 \%$ of soybean were identified correctly. The overall accuracy is $73.29 \%$ with a moderate level of classification agreement (Kappa $=0.53$ ). In addition, Figure 7 shows the growing curves of three crops at the Hongxing farm with variance in 5-day temporal resolution. It is hard to find a day or a few days to identity these three crops by using the single- or multi-date crop mapping method.

By comparing the NDVI curve made by the time serious data with 5-day temporal resolution and daily resolution (Figures 7 and 9), due to missing data or noise in the time series, the NDIV curve from daily data was much closer to the actual growing curve than that from 5-day data, which also affects the classification results. Fortunately, new satellites with $100 \mathrm{~m}$ resolution and daily coverage have already been featured in ESA plans. We believe that this will greatly enhance the accuracy of crop monitoring.

\section{Conclusions}

New satellite images from PROBA-V offer spatial resolutions of $100 \mathrm{~m}-300 \mathrm{~m}$ and a temporal resolution of 1-10 days. Compared with traditional vegetation VI products derived from AVHRR, MODIS, SPOT-Vegetation (250 m-1 km resolution), Landsat and HJ-1 A/B (30 m resolution), PROBA-V provides an intermediate spatial resolution that can replace prior data in application of global crop monitoring. In this study, we attempted using the PROBA-V time series images to identify crops by an ISODATA/MLC unsupervised classification method at two locations with different but typical farming systems. In Yucheng, where winter wheat is followed by summer maize planting, very small 
fields are typical, and, at the Hongxing farm, the crop composition is more complex and it is very common that more than five crops are grown at the same time. In Yucheng, crops were easily identified by both the PROBA-V and the MODIS data, and classification accuracy from PROBA-V data was 3\% better than that from MODIS, due to improved spatial resolution. At the Hongxing farm, where similar crop phenology characteristics were found between two of the three identified major crops, successful identification from MODIS data was not achieved, while PROBA-V performed better. Accordingly, $60.32 \%$ of maize, $84.03 \%$ of soybean and $92.27 \%$ of wheat were identified correctly due to its high temporal and spatial resolution.

To our knowledge, this is the first study that used the new PROBA-V data to identify crops in China. Our results proved that the PROBA-V products have the ability to replace the existing medium resolution remote sensing data on crop mapping, especially in areas with fragmented fields and complex cropping systems. We believe that the PROBA-V global data has broader prospects in other agriculture applications, such as crop condition monitoring and crop yield estimation. Additional work is needed to remove the "bowtie effect" in the time series analysis, and we look forward to the introduction of new satellites with a shorter repeat cycle and higher spatial resolution.

Acknowledgments: This paper was supported by the National Natural Science Foundation for Young Scholars of China (Grant No. 41501474) and the China Grains Administration Special Fund for Public Interest (No. 201313009-2; 201413003-7), Thanks go to Rene Gommes and the anonymous reviewers for reviewing the manuscript and providing comments to improve the manuscript.

Author Contributions: Xin Zhang contributed to the research experiments, analyzed the data, and wrote the paper. Bingfang $\mathrm{Wu}$ conceived the experiments, and responsible for the research analysis. Miao Zhang, Yang Zheng collected and pre-processed the original data. All the co-authors helped to revise the manuscript.

Conflicts of Interest: The authors declare no conflict of interest.

\section{References}

1. Chen, Z.; Li, S.; Ren, J.; Gong, P.; Zhang, M.; Wang, L.; Xiao, S.; Jiang, D. Monitoring and management of agriculture with remote sensing. In Advances in Land Remote Sensing; Springer: Dordrecht, The Netherlands, 2008; pp. 397-421.

2. Macdonald, R.B.; Hall, F.G. Global crop forecasting. Science 1980, 208, 670-679. [CrossRef] [PubMed]

3. Bolton, D.K.; Friedl, M.A. Forecasting crop yield using remotely sensed vegetation indices and crop phenology metrics. Agric. For. Meteorol. 2013, 173, 74-84. [CrossRef]

4. Delécolle, R.; Maas, S.J.; Guérif, M.; Baret, F. Remote sensing and crop production models: Present trends. ISPRS. J. Photogramm. Remote Sens. 1992, 47, 145-161. [CrossRef]

5. Vieira, M.A.; Formaggio, A.R.; Rennó, C.D.; Atzberger, C.; Aguiar, D.A.; Mello, M.P. Object based image analysis and data mining applied to a remotely sensed Landsat time-series to map sugarcane over large areas. Remote Sens. Environ. 2012, 123, 553-562. [CrossRef]

6. Atzberger, C. Advances in remote sensing of agriculture: Context description, existing operational monitoring systems and major information needs. Remote Sens. 2013, 5, 949-981. [CrossRef]

7. Atzberger, C. Correction: Atzberger, C. Advances in remote sensing of agriculture: context description, existing operational monitoring systems and major information needs. Remote Sens. 2013, 5, 949-981. Remote Sens. 2013, 5, 4124. [CrossRef]

8. Wardlow, B.D.; Egbert, S.L. Large-area crop mapping using time-series MODIS 250m NDVI data: An assessment for the U.S. Central Great Plains. Remote Sens. Environ. 2008, 112, 1096-1116. [CrossRef]

9. De Wit, A.J.W.; Clevers, J.G.P.W. Efficiency and accuracy of per-field classification for operational crop mapping. Int. J. Remote Sens. 2004, 25, 4091-4112. [CrossRef]

10. Reed, B.C.; Schwartz, M.D.; Xiao, X. Remote sensing phenology. In Phenology of Ecosystem Processes: Applications in Global Change Research; Springer: New York, NY, USA, 2003; pp. 365-381.

11. Brown, M.E.; Beurs, K.M.D.; Marshall, M. Global phenological response to climate change in crop areas using satellite remote sensing of vegetation, humidity and temperature over 26 years. Remote Sens. Environ. 2012, 126, 174-183. [CrossRef] 
12. Huete, A.; Didan, K.; Miura, T.; Rodriguez, E.P.; Gao, X.; Ferreira, L.G. Overview of the radiometric and biophysical performance of the MODIS vegetation indices. Remote Sens. Environ. 2002, 83, 195-213. [CrossRef]

13. Quarmby, N.A.; Milnes, M.; Hindle, T.L.; Silleos, N. Use of multi-temporal NDVI measurements from AVHRR data for crop yield estimation and prediction. Int. J. Remote Sens. 1993, 14, 199-210. [CrossRef]

14. Groten, S.M.E. NDVI-Crop monitoring and early yield assessment of Burkina Faso. Int. J. Remote Sens. 1993, 14, 1495-1515. [CrossRef]

15. Hansen, M.C.; Loveland, T.R. A review of large area monitoring of land cover change using Landsat data. Remote Sens. Environ. 2012, 122, 66-74. [CrossRef]

16. Pax, M. The effect of spatial resolution on the ability to monitor the status of agricultural lands. Remote Sens. Environ. 1997, 61, 210-220.

17. Mukashema, A.; Veldkamp, A.; Vrieling, A. Automated high resolution mapping of coffee in Rwanda using an expert Bayesian network. Int. J. Appl. Earth Obs. Geoinf. 2014, 33, 331-340. [CrossRef]

18. Duveiller, G.; Defourny, P. A conceptual framework to define the spatial resolution requirements for agricultural monitoring using remote sensing. Remote Sens. Environ. 2010, 114, 2637-2650. [CrossRef]

19. Galford, G.L.; Mustard, J.F.; Melillo, J.; Gendrin, A.; Cerri, C.C.; Cerri, C.E.P. Wavelet analysis of MODIS time series to detect expansion and intensification of row-crop agriculture in Brazil. Remote Sens. Environ. 2008, 112, 576-587. [CrossRef]

20. Vrieling, A.; Beurs, K.M.D.; Brown, M.E. Variability of African farming systems from phenological analysis of NDVI time series. Clim. Chang. 2011, 109, 455-477. [CrossRef]

21. Sakamoto, T.; Wardlow, B.D.; Gitelson, A.A.; Verma, S.B.; Suyker, A.E.; Arkebauer, T.J. A two-step filtering approach for detecting maize and soybean phenology with time-series MODIS data. Remote Sens. Environ. 2010, 114, 2146-2159. [CrossRef]

22. Zhang, X.; Friedl, M.A.; Schaaf, C.B.; Strahler, A.H.; Hodges, J.C.F.; Gao, F.; Reed, B.C.; Huete, A. Monitoring vegetation phenology using MODIS. Remote Sens. Environ. 2003, 84, 471-475. [CrossRef]

23. Atzberger, C.; Eilers, P.H.C. A time series for monitoring vegetation activity and phenology at 10-daily time steps covering large parts of South America. Int. J. Digit. Earth 2011, 4, 365-386. [CrossRef]

24. Kastens, J.H.; Kastens, T.L.; Kastens, D.L.A.; Price, K.P.; Martinko, E.A.; Lee, R.Y. Image masking for crop yield forecasting using AVHRR NDVI time series imagery. Remote Sens. Environ. 2005, 99, 341-356. [CrossRef]

25. Pan, Y.; Li, L.; Zhang, J.; Liang, S.; Zhu, X.; Sulla-Menashe, D. Winter wheat area estimation from MODIS-EVI time series data using the Crop Proportion Phenology Index. Remote Sens. Environ. 2012, 119, 232-242. [CrossRef]

26. Pan, Z.; Huang, J.; Zhou, Q.; Wang, L.; Cheng, Y.; Zhang, H.; Blackburn, G.A.; Yan, J.; Liu, J. Mapping crop phenology using NDVI time-series derived from HJ-1 A/B data. Int. J. Appl. Earth Obs. Geoinf. 2015, 34, 188-197. [CrossRef]

27. Zheng, B.; Myint, S.W.; Thenkabail, P.S.; Aggarwal, R.M. A support vector machine to identify irrigated crop types using time-series Landsat NDVI data. Int. J. Appl. Earth Obs. Geoinf. 2015, 34, 103-112. [CrossRef]

28. Jinwei, D.; Xiangming, X.; Michael, A.M.; Geli, Z.; Yuanwei, Q.; David, T.; Chandrashekhar, B.; Berrien, M. Mapping paddy rice planting area in northeastern Asia with Landsat 8 images, phenology-based algorithm and Google Earth Engine. Remote Sens. Environ. 2016, 185, 142-154.

29. Breon, F.M.; Vermote, E. Correction of MODIS surface reflectance time series for BRDF effects. Remote Sens. Environ. 2012, 125, 1-9. [CrossRef]

30. Chen, J.; Jönsson, P.; Tamura, M.; Gu, Z.; Matsushita, B.; Eklundh, L. A simple method for reconstructing a high-quality NDVI time-series data set based on the Savitzky-Golay filter. Remote Sens. Environ. 2004, 91, 332-344. [CrossRef]

31. Savitzky, A.; Golay, M.J.E. Smoothing and differentiation of data by simplified least squares procedures. Anal. Chem. 1964, 36, 1627-1639. [CrossRef]

32. Viovy, N.; Arino, O.; Belward, A.S. The Best Index Slope Extraction (BISE): A method for reducing noise in NDVI time-series. Int. J. Remote Sens. 1992, 13, 1585-1590. [CrossRef]

33. Michishita, R.; Jin, Z.; Chen, J.; Xu, B. Empirical comparison of noise reduction techniques for NDVI time-series based on a new measure. ISPRS J. Photogramm. Remote Sens. 2014, 91, 17-28. [CrossRef]

34. Cracknell, A.P. The Advanced Very High Resolution Radiometer (AVHRR); CRC Press: BocaRaton, FL, USA. 1997; p. 526. 
35. Jakubauskas, M.E.; Legates, D.R.; Kastens, J.H. Crop identification using harmonic analysis of time-series AVHRR NDVI data. Comput. Electron. Agric. 2003, 37, 127-139. [CrossRef]

36. Xiao, X.; Boles, S.; Liu, J.; Zhuang, D.; Frolking, S.; Li, C.; Salas, W.; Iii, B.M. Mapping paddy rice agriculture in southern China using multi-temporal MODIS images. Remote Sens. Environ. 2005, 95, 480-492. [CrossRef]

37. Justice, C.O.; Vermote, E.; Townshend, J.R.G.; Defries, R.; Roy, D.P.; Hall, D.K.; Salomonson, V.V.; Privette, J.L.; Riggs, G.; Strahler, A. The Moderate Resolution Imaging Spectroradiometer (MODIS): Land remote sensing for global change research. IEEE Trans. Geosci. Remote Sens. 1998, 36, 1228-1249. [CrossRef]

38. Lunetta, R.S.; Shao, Y. Monitoring agricultural cropping patterns across the Laurentian Great Lakes Basin using MODIS-NDVI data. Int. J. Appl. Earth Obs. Geoinf. 2010, 12, 81-88. [CrossRef]

39. Atzberger, C.; Formaggio, A.R.; Shimabukuro, Y.E.; Udelhoven, T.; Mattiuzzi, M.; Sanchez, G.A.; Arai, E. Obtaining crop-specific time profiles of NDVI: The use of unmixing approaches for serving the continuity between SPOT-VGT and PROBA-V time series. Int. J. Remote Sens. 2014, 35, 2615-2638. [CrossRef]

40. Maisongrande, P.; Duchemin, B.; Dedieu, G. VEGETATION/SPOT: An operational mission for the Earth monitoring; presentation of new standard products. Int. J. Remote Sens. 2004, 25, 9-14. [CrossRef]

41. Estrella, N.; Sparks, T.H.; Menzel, A. Effects of temperature, phase type and timing, location, and human density on plant phenological responses in Europe. Clim. Res. 2009, 39, 235-248. [CrossRef]

42. Bégué, A.; Arvor, D.; Lelong, C.; Vintrou, E.; Simões, M. Agricultural systems studies using remote sensing. In Remote Sensing Handbook, 2nd ed.; CRC Press: BocaRaton, FL, USA, 2015; pp. 113-128.

43. Schroeder, T.A.; Wulder, M.A.; Healey, S.P.; Moisen, G.G. Mapping wildfire and clearcut harvest disturbances in boreal forests with Landsat time series data. Remote Sens. Environ. 2011, 115, 1421-1433. [CrossRef]

44. Zhang, M.; Zhou, Q.; Chen, Z.; Jia, L.; Yong, Z.; Cai, C. Crop discrimination in Northern China with double cropping systems using Fourier analysis of time-series MODIS data. Int. J. Appl. Earth Obs. Geoinf. 2008, 10, 476-485.

45. Sakamoto, T.; Yokozawa, M.; Toritani, H.; Shibayama, M.; Ishitsuka, N.; Ohno, H. A crop phenology detection method using time-series MODIS data. Remote Sens. Environ. 2005, 96, 366-374. [CrossRef]

46. Tarnavsky, E.; Garrigues, S.; Brown, M.E. Multiscale geostatistical analysis of AVHRR, SPOT-VGT, and MODIS global NDVI products. Remote Sens. Environ. 2008, 112, 535-549. [CrossRef]

47. Fensholt, R.; Rasmussen, K.; Nielsen, T.T.; Mbow, C.; Rasmussen, K.; Nielsen, T.T.; Mbow, C. Evaluation of earth observation based long term vegetation trends-Intercomparing NDVI time series trend analysis consistency of Sahel from AVHRR GIMMS, Terra MODIS and SPOT VGT data. Remote Sens. Environ. 2009, 113, 1886-1898. [CrossRef]

48. Aschbacher, J.; Milagro-Pérez, M.P. The European Earth monitoring (GMES) programme: Status and perspectives. Remote Sens. Environ. 2012, 120, 3-8. [CrossRef]

49. Dierckx, W.; Sterckx, S.; Benhadj, I.; Livens, S.; Duhoux, G.; Achteren, T.V.; Francois, M.; Mellab, K.; Saint, G. PROBA-V mission for global vegetation monitoring: Standard products and image quality. Int. J. Remote Sens. 2014, 35, 2589-2614. [CrossRef]

50. Petitjean, F.; Inglada, J.; Gancarski, P. Assessing the quality of temporal high-resolution classifications with low-resolution satellite image time series. Int. J. Remote Sens. 2014, 35, 2693-2712. [CrossRef]

51. Roumenina, E.; Atzberger, C.; Vassilev, V.; Dimitrov, P.; Kamenova, I.; Banov, M.; Filchev, L.; Jelev, G. Single- and multi-date crop identification using PROBA-V 100 and $300 \mathrm{~m} \mathrm{S1}$ products on Zlatia test site, Bulgaria. Remote Sens. 2015, 7, 13843-13862. [CrossRef]

52. Vassilev, V.S. Crop identification mapping on the arable territory of Bulgaria using multi-temporal $100 \mathrm{~m}$ PROBA-V NDVI data for 2014. C. R. Acad. Bulg. Sci. 2015, 68, 761-766.

53. Memarsadeghi, N.; Mount, D.M.; Netanyahu, N.S.; Le Moigne, J. A fast implementation of the ISODATA clustering algorithm. Int. J. Comput. Geom. Appl. 2007, 17, 71-103. [CrossRef]

54. Ball, G.H.; Hall, D.J. ISODATA, A Novel Method of Data Analysis and Pattern Classification; Technical Report for Stanford RI; Stanford Research Institute: Menlo Park, CA, USA, 1965.

55. Eerens, H.; Haesen, D.; Rembold, F.; Urbano, F.; Tote, C.; Bydekerke, L. Image time series processing for agriculture monitoring. Environ. Model. Softw. 2014, 53, 154-162. [CrossRef]

56. Jönsson, P.; Eklundh, L. TIMESAT-A program for analyzing time-series of satellite sensor data. Comput. Geosci. 2004, 30, 833-845. [CrossRef]

57. Global Earth Observation System of Systems (GEOSS), Joint Experiment of Crop Assessment and Monitoring. Available online: http:/ /www.jecam.org/ (accessed on 18 August 2014). 
58. Liu, Y.; Yang, R.; Long, H.; Gao, J.; Wang, J. Implications of land-use change in rural China: A case study of Yucheng, Shandong province. Land Use Policy 2014, 40, 111-118. [CrossRef]

59. Cheng, Z.; Meng, J.; Wang, Y. Improving spring maize yield estimation at field scale by assimilating time-series HJ-1 CCD data into the WOFOST model using a new method with fast algorithms. Remote Sens. 2016, 8, 303. [CrossRef]

60. Wolters, E.; Dierckx, W.; Swinnen, E. PROBA-V Products User Manual v1.3; VITO: Mol, Belgium, 2014. Available online: proba-v.vgt.vito.be/sites/default/files/Product_User_Manual.pdf (accessed on 31 August 2015).

61. Zhang, M.; Wu, B.; Yu, M.; Zou, W.; Zheng, Y. Crop condition assessment with adjusted NDVI using the uncropped Arable Land Ratio. Remote Sens. 2014, 6, 5774-5794. [CrossRef]

62. Zhang, M.; Wu, B.; Meng, J. Quantifying winter wheat residue biomass with a spectral angle index derived from China Environmental Satellite data. Int. J. Appl. Earth Obs. Geoinf. 2014, 32, 105-113. [CrossRef]

63. Atzberger, C.; Eilers, P.H.C. Evaluating the effectiveness of smoothing algorithms in the absence of ground reference measurements. Int. J. Remote Sens. 2011, 32, 3689-3709. [CrossRef]

64. Swets, D.L.; Reed, B.C.; Rowland, J.D.; Marko, S.E. A weighted least-squares approach to temporal NDVI smoothing. In Proceedings of the 1999 ASPRS Annual Conference: From Image to Information, Portland, OR, USA, 17-21 May 1999; pp. 17-21.

65. Reed, B.C.; Brown, J.F.; Vanderzee, D.; Loveland, T.R.; Merchant, J.W.; Ohlen, D.O. Measuring phenological variability from satellite imagery. J. Veg. Sci. 1994, 5, 703-714. [CrossRef]

66. Jonsson, P.; Eklundh, L. Seasonality extraction by function fitting to time-series of satellite sensor data. IEEE Trans. Geosci. Remote Sens. 2002, 40, 1824-1832. [CrossRef]

67. Ren, R.; Guo, S.; Gu, L. Fast bowtie effect elimination for MODIS L 1B data. J. China Univ. Posts Telecommun. 2010, 17, 120-126. [CrossRef]

68. Baruth, B.; Royer, A.; Klisch, A.; Genovese, G. The use of remote sensing within the MARS crop yield monitoring system of the European Commission. Int. Arch. Photogramm. Remote Sens. Spat. Inf. Sci. 2008, 37, 935-940.

69. Pittman, K.; Hansen, M.C.; Becker-Reshef, I.; Potapov, P.V.; Justice, C.O. Estimating global cropland extent with multi-year MODIS data. Remote Sens. 2010, 2, 1844-1863. [CrossRef]

70. Fritz, S.; You, L.; Bun, A.; See, L.; Mccallum, I.; Schill, C.; Perger, C.; Liu, J.; Hansen, M.; Obersteiner, M. Cropland for sub-Saharan Africa: A synergistic approach using five land cover data sets. Geophys. Res. Lett. 2011, 38, 155-170. [CrossRef]

71. Fritz, S.; See, L.; Mccallum, I.; You, L.; Bun, A.; Moltchanova, E.; Duerauer, M.; Albrecht, F.; Schill, C.; Perger, C. Mapping global cropland and field size. Glob. Chang. Biol. 2015, 21, 1980-1992. [CrossRef] [PubMed]

72. Peña-Barragán, J.M.; Ngugi, M.K.; Plant, R.E.; Six, J. Object-based crop identification using multiple vegetation indices, textural features and crop phenology. Remote Sens. Environ. 2011, 115, 1301-1316. [CrossRef]

73. Sterckx, S.; Benhadj, I.; Duhoux, G.; Livens, S.; Dierckx, W.; Goor, E.; Adriaensen, S.; Heyns, W.; Hoof, K.V.; Strackx, G. The PROBA-V mission: Image processing and calibration. Int. J. Remote Sens. 2014, 35, 2565-2588. [CrossRef]

74. Mica, S.; Galli, L.; Duhoux, G.; Livens, S.; Jovanovic, V.; Giustiniani, A.; Dries, J.C.; Zender, J.; Santandrea, S. PROBA-V geometric calibration. In Proceedings of the 2012 IEEE International Geoscience and Remote Sensing Symposium, Munich, Germany, 22-27 July 2012; pp. 1034-1037.

75. Xiong, J.; Toller, G.; Chiang, V.; Sun, J.; Esposito, J.; Barnes, W. MODIS Level $1 b$ Algorithm Theoretical Basis Document; Goddard Space Flight Center, National Aeronautics and Space Administration: Greenbelt, MD, USA, 2005.

76. Sayer, A.M.; Hsu, N.C.; Bettenhausen, C. Implications of MODIS bowtie distortion on aerosol optical depth retrievals, and techniques for mitigation. Atmos. Meas. Tech. Discuss. 2015, 8, 8727-8752. [CrossRef]

77. Gómezlandesa, E.; Rango, A.; Bleiweiss, M. An algorithm to address the MODIS bowtie effect. Can. J. Remote Sens. 2004, 30, 644-650. [CrossRef]

78. Li, Y.; Shi, Z. A research on an algorithm for removing bowtie effect. In Proceedings of the 2011 Symposium of Photonics and Optoelectronics (SOPO), Wuhan, China, 16-18 May 2011; pp. 1-4.

(C) 2016 by the authors; licensee MDPI, Basel, Switzerland. This article is an open access article distributed under the terms and conditions of the Creative Commons Attribution (CC-BY) license (http://creativecommons.org/licenses/by/4.0/). 